Esta revista forma parte del acervo de la Biblioteca Jurídica Virtual del Instituto de Investigaciones Jurídicas de la UNAM http://www.juridicas.unam.mx

https://biblio.juridicas.unam.mx

https://revistas.juridicas.unam.mx

DOI: http://dx.doi.org/10.22201/iij.24484873e.2020.157.15235

\title{
ESTUDIOS LEGISLATIVOS
}

Universidad Nacional Autónoma de México, IIJ-BJV, 2020

http://revistas.juridicas.unam.mx/index.php/derecho-comparado/issue/archive 


\title{
OJOS QUE SÍ VEN: LA REGULACIÓN DE LA PUBLICIDAD ESTATAL: LEGGIONES DESDE EL PERÚ Y EL DERECHO COMPARADO*
}

\author{
Andrés CALDERÓN** \\ Adriana ASCUE*** \\ Eduardo DIBÓS****
}

\begin{abstract}
SumARIO: I. Introducción. II. Regulación de la publicidad estatal en el Perú. III. Regulación de la publicidad estatal en Canadá. IV. Regulación de la publicidad estatal en Uruguay. V. Regulación de la publicidad estatal en México. VI. Análisis comparado a la luz de los principios de la Relatoría Especial para la Libertad de Expresión sobre publicidad oficial. VII. Conclusión. VIII. Bibliografia.
\end{abstract}

\section{INTRODUCGIÓN}

Dentro del continente americano, probablemente ningún otro país haya experimentado más controversias sobre la regulación de la publicidad estatal que el Perú.

* Estudio legislativo recibido el 3 de diciembre de 2019 y aceptado para su publicación el 30 de abril de 2020.

** ORCID: 0000-0001-9922-6517. Profesor y director de la Clínica Jurídica de Libertades Informativas y Transparencia de la Universidad del Pacífico (Perú). Master of Laws por la Universidad de Yale (Estados Unidos). Abogado por la Pontificia Universidad Católica del Perú. Investigador asociado del Centro de Estudios en Libertad de Expresión y Acceso a la Información de la Universidad de Palermo (Argentina). Columnista de El Comercio (Perú) y como invitado de El Universal (México). Correo electrónico: a.calderonl@up.edu.pe.

*** ORCID: 0000-0003-3923-157. Estudiante de la Facultad de Derecho de la Universidad del Pacifico (Perú). Asistente de investigación del Centro de Investigación de la Universidad del Pacífico. Colaboradora voluntaria en la Clínica Jurídica de Libertades Informativas y Transparencia de la Universidad del Pacífico. Correo electrónico: a.ascuedel aguila@alum.up.edu.pe.

**** ORCID: 0000-0002-2166-7547. Estudiante de la Facultad de Derecho de la Universidad del Pacífico (Perú). Colaborador voluntario en la Clínica Jurídica de Libertades Informativas y Transparencia de la Universidad del Pacífico. Correo electrónico: e.dibos figueroa@alum.up.edu.pe.

Boletín Mexicano de Derecho Comparado, nueva serie, año LII, núm. 157, enero-abril de 2020, pp. 355-383. 
Perú era uno de los pocos países en la región que contaba con una legislación general sobre publicidad estatal (Ley que Regula la Publicidad Estatal, Ley 28874, 2006). Sin embargo, en los últimos dos años este país ha visto la presentación de hasta trece proyectos de leyes sobre la materia, ha sido testigo de la aprobación accidentada y atropellada de una ley que prohibía la contratación de medios de comunicación privados para la difusión de las campañas publicitarias estatales (Ley que Regula el Gasto de Publicidad del Estado Peruano, Ley 30793, 2018) y ha sido notificado de la declaración de inconstitucionalidad de aquella norma por parte del Tribunal Constitucional. ${ }^{1}$

A pesar de ser un tema de amplio interés y controversia, la literatura académica no ha acompañado el vertiginoso ritmo de los legisladores y magistrados peruanos. A nivel local, sólo se cuenta con un trabajo monográfico que proporciona algunos datos estadísticos sobre la inversión publicitaria (Ruiz 2017), mas no plantea una discusión sobre política pública.

A nivel internacional, encontramos tres tipos de estudios, principalmente. Un primer grupo analiza la regulación y la práctica estatal del gasto publicitario que resalta los problemas que una excesiva discrecionalidad ha generado, hasta el punto de convertirse en algunos casos en un mecanismo de censura indirecta a medios de comunicación (WANIFRA 2014; WAN-IFRA 2015; Buquet, Lanza y Rabinovich 2012). Otro grupo de estudios califican más bien como reportes que miden el gasto publicitario en sus respectivos países y su orientación (Becerra 2011), o narran la evolución histórica de las campañas publicitarias gubernamentales (Young 2007). Finalmente, tenemos un tercer grupo de estudios que plantean un análisis comparado de la legislación en materia de publicidad estatal (ADC 2008) y proponen algunos principios o reglas básicas en la materia (ADC 2006).

El presente estudio busca aportar a la literatura de análisis comparado sobre la legislación en materia de publicidad estatal. Con dicho fin, el segundo apartado resume los principales aspectos del marco legal peruano, enfocándose principalmente en la Ley 28874, Ley que regula la Publicidad Estatal, puesto que la posterior Ley 30793 — declarada recientemente inconstitucional - no aportaba aspectos regulatorios que pudieran ser

1 Tribunal Constitucional, Pleno Jurisdiccional Expedientes 0012-2018-PI/TC y 0013-2018-PI/TC, 2018. 
analizados, más allá de la prohibición y penalización amplia de la inversión publicitaria en medios de comunicación privados. Los apartados tercero, cuarto y quinto hacen lo propio, siguiendo una misma metodología de síntesis descriptivo, con aquellos países que cuentan con legislaciones transversales sobre publicidad oficial, como Canadá, Uruguay (que cuenta con un proyecto de ley aprobado por la primera cámara legislativa) y México, respectivamente; el sexto apartado plantea una contribución singular a los estudios existentes en la materia, al realizar una evaluación comparada de las legislaciones de Perú, Canadá, Uruguay y México, a la luz de las exigencias que plantea la Relatoría Especial para la Libertad de Expresión de la Comisión Interamericana de Derechos Humanos (RELE) en sus "Principios sobre Regulación de la Publicidad Oficial y Libertad de Expresión” (RELE 2012). Luego de este análisis, concluimos.

\section{Regulación de LA PUblicidad eStatal EN EL Perú}

\section{Finalidad y ámbito de aplicación de la regulación}

Hasta antes de junio de 2018, cuando se promulgó la Ley 30793, "Ley que Regula el Gasto de Publicidad del Estado Peruano" — que más que regular prohibía la contratación de medios de comunicación privados para la difusión de campañas publicitarias del Estado, que luego fue declarada inconstitucional-, el Perú ya contaba con una legislación que establecía ciertas reglas y principios para la elaboración, contratación y difusión de la publicidad estatal. Esta norma era la Ley 28874, que regulaba la publicidad estatal.

Aprobada en 2006, la Ley que regula la publicidad estatal fue una norma pionera en América en la materia, sólo después de Canadá. Sin embargo, como apunta la RELE, esta norma no logró "eliminar la discrecionalidad en la distribución de la pauta publicitaria, en parte como consecuencia de su falta de reglamentación" (RELE 2012).

El artículo 2o. de la Ley 28874 limita su ámbito de aplicación a "los rubros de publicidad institucional de las entidades y dependencias que conforman el gobierno central, regional o local". La publicidad estatal es definida como aquella que promueve "conductas de relevancia social, tales como el ahorro de energía eléctrica, la preservación del medio ambiente, el pago de impuestos, entre otras". En oposición, el mismo artículo excluye de su espectro de control a cierto tipo de publicaciones como "no- 
tas de prensa, avisos sobre procedimientos a convocarse en el marco de la Ley de Contrataciones y Adquisiciones del Estado, y la publicación de normas que en cumplimiento de sus funciones desarrollan las entidades y dependencias del gobierno nacional, regional o local". Una excepción poco sustentada, pues más allá de que el contenido de estos avisos sería neutral por naturaleza, sí resultaría importante controlar la forma en que se contratan estos avisos, los criterios de distribución a través de medios de difusión, así como la rendición de cuentas respecto de estos gastos.

En lo que respecta a los objetivos, la Ley advierte que la inversión publicitaria estatal debe orientarse a los fines institucionales de cada entidad, como la "promoción de la imagen institucional, la comunicación de sus planes y programas, o a la venta de bienes y servicios". Otras finalidades expresamente amparadas por la ley son la de promoción de una cultura preventiva en asuntos relacionados con la seguridad pública, salubridad y manejo de recursos naturales, la difusión de información en materia de salud, la promoción de la participación ciudadana y la difusión de leyes.

Además, se prohíbe expresamente el gasto publicitario para determinadas acciones como beneficiar a algún candidato a un cargo de elección popular o a algún partido político. También se proscribe que algún funcionario de la entidad pública anunciante aparezca en los mensajes o campañas publicitarias.

Un aspecto resaltante es que la Ley se enfoca únicamente en la relación entre Estado y medios de comunicación, y no establece las mismas pautas u obligaciones para la contratación de empresas dedicadas a la creación y producción de publicidad, o agencias de medios que funcionan como intermediarios entre el anunciante y los medios de comunicación.

En la misma Ley 28874 no se establece expresamente alguna limitación a la difusión de publicidad estatal durante los periodos de campañas electorales, pero sí en la Ley de Radio y Televisión (Ley 28278), que prohíbe que entidades estatales puedan contratar avisos publicitarios una vez que se ha efectuado la convocatoria a comicios electorales generales, regionales o municipales, con la excepción de los organismos que integran el sistema electoral (salvo autorización expresa del Jurado Nacional de Elecciones).

\section{Contratación y distribución de publicidad}

Más allá del mandato de "transparencia y racionalidad en el uso de los recursos públicos para la contratación de servicios de publicidad en Esta obra está bajo una Licencia Creative Commons Atribución-NoComercial-SinDerivar 4.0 Internacional, IIJ-UNAM.

Boletín Mexicano de Derecho Comparado, núm. 157, enero-abril de 2020, pp. 355-383. 
prensa escrita, radio y televisión" al que hace referencia el artículo 1o. de la Ley 28874, no se establece ningún otro principio para la contratación de publicidad estatal. Así, no aparecen en la ley fundamentos rectores, como eficiencia, competencia, transparencia o no discriminación.

La Ley 28874 no prevé un mecanismo particular para la contratación de publicidad. Sin embargo, el artículo 27, literal g, de la Ley 30025, Ley de Contrataciones con el Estado, señala que

... para los servicios de publicidad que prestan al Estado los medios de comunicación televisiva, radial, escrita o cualquier otro medio de comunicación, se podrá contratar directamente con el proveedor. Esto significa que no se requerirá de un procedimiento de licitación, concurso o similar para la elección del medio de comunicación donde se difundirá la publicidad estatal.

Otros servicios relacionados, en cambio, como la creación y producción publicitaria, así como la elección de una agencia o central de medios que coordine la contratación de pauta publicitaria en medios de comunicación, no están, en principio, exentos de seguir los procedimientos competitivos de elección y contratación previstos en la Ley de Contrataciones con el Estado.

Pese a la ausencia de un procedimiento reglado para la contratación de publicidad estatal, la Ley 28874 sí exige ciertos pasos previos a la aprobación de la inversión publicitaria y selección del canal de difusión. En primer lugar, el artículo 3o. pide la elaboración de un plan de estrategia publicitaria (PEP), que vaya acorde con las competencias asignadas a la entidad que desea difundir la publicidad y adecuado a las prioridades y objetivos señalados en los programas sectoriales. Este plan debe contener la descripción y justificación de las campañas publicitarias planificadas para ese año.

También se requiere que la entidad pública identifique los medios de comunicación donde se realizará la difusión de la publicidad y que se justifique técnicamente su elección "de acuerdo con el público objetivo y la finalidad que se quiere lograr, la cobertura, duración de la campaña, equilibrio informativo e impacto de los mismos". En la práctica, las entidades públicas han venido haciendo alusión a estos criterios para sustentar los medios de comunicación escogidos para la difusión de la publicidad, sin establecer un orden de prioridad o ponderación entre estos factores. Fi- 
nalmente, el mismo artículo 3o. de la Ley 28874 requiere a las entidades, presentar un proyecto de presupuesto para ejecutar las campañas publicitarias.

\section{Control externo y transparencia}

Los planes de estrategia publicitaria, así como la descripción y justificación de las campañas, los medios de comunicación elegidos y el proyecto de presupuesto, son documentos de acceso al público. Sin embargo, no se ha establecido una (deseable) obligación de publicarlos o difundirlos activamente.

Las entidades públicas sí deben publicar, en cambio, los contratos de publicidad celebrados en sus portales electrónicos, según el artículo 6o. de la Ley 28874. Al no distinguirse entre qué tipo de contratos, se entiende que éstos deberían incluir no sólo los contratos de difusión, sino también los de creación y producción publicitaria, y los de intermediación para la colocación de pauta publicitaria.

Asimismo, se establecen dos obligaciones adicionales, que tienen como finalidad un control ex post a la realización de las campañas publicitarias. Éstas son: la justificación ante el Sistema Nacional de Control de la elección de determinada empresa para la elaboración de la publicidad, y realizar una evaluación de resultados de la publicidad contratada vía indicadores de desempeño, la cual también deberá ser remitida al Sistema Nacional de Control (artículo 6o. de la Ley 28874). El Sistema Nacional de Control es dirigido por la Contraloría General de la República. Sin embargo, no se ha previsto qué órgano de la Contraloría es el responsable de recibir esta información. Otra falencia es que no se ha previsto qué acciones puede tomar la Contraloría ante el incumplimiento de alguna de las obligaciones de la Ley 28874 ni se han contemplado sanciones ante una eventual infracción legal.

Finalmente, en la Ley de Radio y Televisión (Ley 28278) se establecen algunas obligaciones adicionales de transparencia para las entidades públicas, como difundir en sus páginas web institucionales las tarifas por la contratación de los espacios, la duración de la pauta publicitaria y los criterios de selección. Asimismo, la Ley 28278 prevé en su artículo 51 que algunas entidades públicas (Presidencia del Consejo de Ministros, organismos autónomos y gobiernos regionales y locales) envíen trimestral-

Esta obra está bajo una Licencia Creative Commons

Atribución-NoComercial-SinDerivar 4.0 Internacional, IIJ-UNAM.

Boletín Mexicano de Derecho Comparado, núm. 157, enero-abril de 2020, pp. 355-383. 
mente al Congreso "la información desagregada y consolidada sobre los contratos y gastos referidos a la publicidad estatal" dentro de los diez días posteriores a cada trimestre. También se obliga a las empresas de radiodifusión que hayan transmitido publicidad estatal, a remitir "la información pertinente" a la Presidencia del Consejo de Ministros de forma mensual.

\section{REgUlaCiÓN DE LA PUBLICIDAD ESTATAL EN CANADÁ}

\section{Finalidad y ámbito de aplicación de la regulación}

La publicidad estatal en Canadá está regulada por la Política de Comunicaciones e Identidad Federal (Policy on Communications and Federal Identity), adoptada por el gobierno federal, que se encuentra vigente desde el 11 de mayo de 2016. Esta norma especial, establecida a través de una reglamentación de la Finantial Administration Act (R. S. C. 1985, c. F-11, 1985), contiene las pautas de publicidad y comunicación de políticas, programas, servicios e iniciativas llevadas a cabo por el gobierno canadiense. La normativa circunscribe su ámbito de aplicación a las veinte entidades que conforman el gabinete (19 ministerios o departments y el Consejo del Tesoro) y sus órganos.

La Directiva de Administración de Comunicaciones complementa la política de comunicaciones. En virtud del artículo 6o., inciso 11, de la Directiva, la regulación canadiense incluye en su alcance a "todas aquellas actividades relacionadas con la producción y colocación de publicidad, incluida la planificación de campañas, desarrollo creativo, pruebas preliminares, producción, planificación de medios, colocación de publicidad y evaluación posterior", es decir, abarca todas las etapas de creación y difusión de publicidad.

La regulación considera que toda publicidad oficial debe ser objetiva, no partidista, clara y escrita en un lenguaje sencillo. En este sentido, el artículo 4o., inciso 3, de la Política de Comunicaciones, señala que la publicidad debe ser no partidista, entendida ésta como "objetiva, imparcial y libre de lemas, imágenes o identificadores de partidos políticos". Asimismo, prohíbe que la comunicación contenga el nombre, la voz o imagen de algún funcionario (ya sea éste presidente, ministro o parlamentario), y proscribe que el color primario del partido de gobierno se use de manera predominante en la publicidad. Además, la Política de Comunicaciones 
prohíbe las actividades de publicidad estatal en los 90 días previos a la fecha de una elección general.

La labor de comunicación estatal en Canadá no se limita a la difusión de información. También se establece una responsabilidad del gobierno, de comunicarse con sus ciudadanos "para ayudar a proteger sus intereses y bienestar, y de promover a Canadá como un país próspero, diverso y acogedor". El artículo 6o., inciso 11, de la Directiva también plantea utilizar preferentemente herramientas digitales y plataformas en línea, como redes sociales y páginas web, con el fin de satisfacer las necesidades informativas de la ciudadanía canadiense.

\section{Contratación y distribución de publicidad}

Con el fin de que los procesos sean abiertos y transparentes, la Directiva proporciona las reglas para administrar y coordinar las comunicaciones, al tiempo que detalla los procedimientos de contratación y asignación de publicidad estatal, investigación de opinión pública, uso de redes sociales y comunicaciones online.

La publicidad en Canadá se guía por el principio digital first. Durante el periodo de publicidad de 2015, por ejemplo, el gasto de publicidad oficial en medios digitales superó por primera vez en la historia a lo colocado en televisión, tendencia que se mantuvo en el periodo fiscal de 2016-2017, en el que la publicidad digital representó el 54.7\% del presupuesto total (PSPG 2018).

Diversas entidades intervienen en el proceso de adjudicación de la publicidad estatal. En palabras del director general del Ministerio de Servicios Públicos y Compras de Canadá, Marc Saint-Pierre: "no sería posible que un ministerio pueda elaborar una campaña de publicidad estatal sin antes haber trabajado conjuntamente con, por lo menos, otras tres entidades del gobierno" (House of Commons Canada 2017). Así, se establece una dinámica de checks and balances en la gestión de los recursos.

Las campañas publicitarias nacen por iniciativa de las propias entidades interesadas en la difusión, que deben elaborar planes de publicidad $e x$ ante, asistidas por una entidad denominada Oficina Privada del Consejo (Privy Council Office, PCO). El PCO es un organismo especializado y técnico que brinda asesoría en la toma de decisiones al primer ministro de Canadá y su gabinete, y responde directamente ante aquél. En cuanto a

Boletín Mexicano de Derecho Comparado, núm. 157, enero-abril de 2020, pp. 355-383. 
actividades de publicidad, el PCO es la entidad encargada de desarrollar un plan anual de publicidad que englobe a su vez los planes y propuestas de cada uno de los ministerios. El PCO brinda el asesoramiento necesario a los ministerios respecto de las prioridades del gobierno, además de los temas y mensajes generales que debe contener la publicidad estatal. El rol de esta entidad en el marco de los procesos de publicidad estatal es constante, pues, además de asesorar a los ministerios, fiscaliza y coordina el cumplimiento del plan anual.

Una vez que las propuestas de campañas - elaboradas conjuntamente por los ministerios y el PCO - son integradas en el plan anual de publicidad, éste es elevado para la aprobación del gabinete en su conjunto. El gabinete, en virtud del plan presentado, determina el monto máximo de financiamiento para las iniciativas publicitarias y confirma la fuente de los fondos. Por lo general, los fondos estatales provienen de una partida financiera estatal denominada Fondo Central de Publicidad (Central Advertising Fund), administrada por el Consejo del Tesoro (Treasury Board), entidad con rango ministerial encargada de la gestión en materias de presupuesto y gasto público, hacienda, tesorería y endeudamiento. El Consejo del Tesoro aprueba en última instancia los montos totales destinados para los conceptos de publicidad estatal (Government of Canada 2016).

Cuando los fondos ya han sido aprobados, los ministerios pasan a trabajar con el Departamento de Servicios Públicos y Compras (Public Services and Procurement Canada o PSPG). El PSPG es el agente estatal de adquisiciones y contrataciones, y concentra un rol protagónico en materia de publicidad estatal, ya que es la entidad encargada de supervisar y llevar a cabo la adjudicación de los contratos de publicidad, según el artículo 8o., inciso 2, literal 7, de la Directiva.

Como regla general, el PSPG se encarga de suscribir los contratos de servicios de publicidad en nombre de todos los ministerios. Los únicos casos en los que se autoriza a éstos a contratar publicidad de manera directa son cuando ésta representa un gasto menor a $\$ 25,000,{ }^{2}$ según el apéndice B, inciso 2, literal 14, de la Directiva. El rol del PSPG puede desagregarse en dos diferentes ámbitos y fases del proceso de contratación: el de la

2 Normalmente se trata de anuncios administrativos, regulatorios y campañas orgánicas de bajo costo en redes sociales. 
contratación de agencias creativas y de producción de publicidad, y la compra de espacios en medios de comunicación.

Cuando los ministerios - luego de trabajar en conjunto con el PCO y el PSPC - consideran que sus campañas se encuentran listas, se da inicio a la fase de contratación de publicidad estatal en los medios de comunicación. La colocación de estas campañas en las distintas plataformas de comunicación es conducida por una agencia de coordinación: Agency of the Record o AOR. De acuerdo con la Directiva, la AOR "es un proveedor del sector privado, seleccionado a través de un proceso competitivo y contratado por el gobierno de Canadá, encargado de negociar, comprar y verificar los tiempos y espacios publicitarios oficiales". El gobierno de Canadá utiliza los servicios de una sola AOR, durante un tiempo determinado. La utilización de la AOR apunta a que el gobierno obtenga una mejor optimización de los recursos al aprovechar el poder de compra colectivo de los ministerios (PSPC 2019b). Centralizar estos servicios en una sola agencia encargada de las estrategias de adquisición y mantenimiento de una estructura de costos predecibles también permite una mejor integración, supervisión, control y generación de informes sobre la contratación de publicidad.

Los ministerios trabajan en estrecha colaboración con la AOR para la selección de los medios de comunicación en función de una serie de criterios de asignación como los objetivos de una campaña, el público y mercado objetivos, los cronogramas y presupuestos asignados.

La normativa canadiense ha establecido criterios más rigurosos para las campañas que superen el costo de un millón. En este sentido, los ministerios involucrados, al igual que el PCO y el PSCP, deben ejecutar procesos adicionales en la etapa previa a la contratación de la publicidad. Para estos casos, las entidades deben desarrollar investigaciones de opinión pública en forma de encuestas y planes de evaluación de impacto previo. Finalmente, para la etapa ex post de las mismas campañas superiores a un millón, ha sido desarrollada una herramienta de evaluación (Advertising Campaign Evaluation Tool o ACET), con el fin de proveer de indicadores de rendimiento a las instituciones que elaboraron la campaña. El ACET busca medir el conocimiento de los ciudadanos canadienses de la campaña publicitaria, medir el nivel de comprensión de los mensajes clave de la campaña, y verificar que el enfoque creativo de la campaña haya llamado la atención de la ciudadanía y del público objetivo. 


\section{Control externo y transparencia}

El PSPC debe publicar un informe anual sobre las actividades publicitarias del gobierno de Canadá, según lo dispone el artículo 8o., inciso 2, literal 5, de la Directiva. Este informe sistematiza y resume los gastos publicitarios y los resultados de campañas importantes (inversiones mayores a \$500,000). Los informes son de acceso simple y gratuito para el público y se encuentran disponibles en los dos idiomas oficiales de manera online. En ellos se puede apreciar el gasto total en publicidad, cuántas entidades publicitaron, cuánto gastó cada una de ellas, el número total de campañas y medios contratados, así como información desagregada por plataforma (televisión, radio, web, etcétera) y por ministerio, entre otros.

El PSPC no divulga información detallada de los importes específicos pagados a cada medio de comunicación a través de su AOR. Esta información es considerada confidencial por el PSPC, pues estiman que podría interferir con las negociaciones contractuales del gobierno y perjudicar la posición competitiva de terceros (PSPC 2019a). Por su parte, las asignaciones presupuestadas y aprobadas por el Consejo del Tesoro son publicadas en el sitio web del Consejo, incluyendo el nombre de la campaña, el gasto total y el ministerio que la encargó. Esta información se actualiza en enero, abril, julio y octubre. Igualmente, todos los contratos de publicidad son publicados en el portal buyandsell.gc.ca, operado por el PSPC. Además, los ministerios y agencias publican todos los contratos mayores a $\$ 10,000$ en los portales de transparencia de sus propios sitios web.

\section{REGULACiÓN DE LA PUbLiCidAD ESTATAL EN URUGUAY}

\section{Finalidad y ámbito de aplicación de la regulación}

El Proyecto de Ley de publicidad oficial que regula la producción, contratación y distribución de la publicidad oficial en cualquier medio fue aprobado por la Cámara de Diputados de la República Oriental del Uruguay en julio de 2018. ${ }^{3}$ Sin embargo, dicho Proyecto de Ley no superó la evaluación de la Cámara de Senadores, y se dispuso su retorno a comisión para estudio (CAinfo 2019).

3 Proyecto de Ley de publicidad oficial que regula la producción, contratación y distribución de la publicidad oficial en cualquier medio, C/387/2015, 2018.

Esta obra está bajo una Licencia Creative Commons Atribución-NoComercial-SinDerivar 4.0 Internacional, IIJ-UNAM. Boletín Mexicano de Derecho Comparado, núm. 157, enero-abril de 2020, pp. 355-383. 
La iniciativa del Proyecto tuvo origen en un anteproyecto preparado por el Centro de Archivos y Acceso a la Información Pública-CAinfo, una organización sin fines de lucro, tomando como base los Principios sobre Regulación de la Publicidad Oficial y Libertad de Expresión de la RELE.

El Proyecto señala que toda la información publicitaria deberá ser veraz, objetiva, clara, transparente, necesaria, oportuna y relevante para aquellos a quienes se dirige, e incluye a distintas modalidades de publicidad en su artículo 3o., como la publicidad de actos administrativos (licitaciones, convocatorias), la publicidad institucional y campañas de bien público, la publicidad de bienes y servicios brindados por el Estado.

Según el artículo lo. de la propuesta normativa, ésta alcanzaría a todo el proceso de creación, contratación y difusión de contenidos publicitarios estatales. El informe de justificación del proyecto plantea la necesidad de establecer criterios claros, objetivos y profesionales para la asignación publicitaria.

Entre las prohibiciones dispuestas por el proyecto normativo se indica que no podrá realizarse publicidad oficial alguna en el periodo de publicidad electoral, según se encuentra establecido en el artículo 1o. de la Ley 17.045 (Ley de Partidos Políticos) de 1998; es decir, durante los 30 días previos a una elección. Como excepción a esta regla general, el Proyecto de Ley (artículo 4o.) no prohíbe, en periodo electoral, la información emanada de las autoridades electorales, la información sobre los servicios o productos prestados por el régimen empresarial estatal, publicidad en casos de emergencia o toda aquella ordenada por normas legales y reglamentarias, así como la publicidad necesaria para el funcionamiento regular de la administración.

\section{Contratación y distribución de publicidad}

El artículo 5o. del Proyecto normativo establece como principios rectores de la contratación de publicidad estatal el interés general, la veracidad, la imparcialidad, la objetividad, la claridad en el mensaje, la profesionalidad, el libre acceso a la información, la transparencia, la publicidad de los actos de gobierno, la eficiencia y la austeridad en el gasto público.

El procedimiento de contratación se realiza a través de licitación pública, por lo que la contratación de publicidad se sujeta a las reglas establecidas por el TOCAF (Texto Ordenado de Contabilidad y Administra-

Esta obra está bajo una Licencia Creative Commons

Atribución-NoComercial-SinDerivar 4.0 Internacional, IIJ-UNAM.

Boletín Mexicano de Derecho Comparado, núm. 157, enero-abril de 2020, pp. 355-383. 
ción Financiera), ley que regula los sistemas de presupuesto público y el control interno de la administración. Se establece, además, que todas las etapas del procedimiento de contratación sean públicas, y se indican tres criterios fundamentales para la contratación de pauta publicitaria.

El primer criterio a ser tomado en cuenta es la "relación entre información o campaña y población objetivo". En segundo orden se encuentra la determinación de los "medios y programas de mayor audiencia, tiraje y lectoría"; en tercer lugar está el "precio de la pauta publicitaria ofrecida por el medio o soporte de comunicación” (artículo 9o. del Proyecto). La normativa señala que vía reglamento se deberá establecer un sistema de puntajes con el cual las entidades públicas deberán basar sus decisiones de asignación de contratos publicitarios con medios de comunicación.

El proyecto normativo uruguayo, asimismo, establece una cuota obligatoria que busca beneficiar a los medios locales y regionales. El artículo 11 del Proyecto dispone que el Estado destine al menos 30\% del presupuesto de publicidad oficial a "medios de comunicación, programas o producciones informativas o periodísticas comerciales o comunitarios, con realización y producción propias y radicados en localidades del interior" (artículo 11). La asignación de esa cuota, no obstante, deberá realizarse de conformidad con los tres criterios mencionados.

Igualmente, la normativa propicia la participación de otras entidades gubernamentales en el procedimiento de contratación dotándolas de nuevas competencias y responsabilidades. La Agencia de Compras y Contrataciones del Estado (ACCE) podrá brindar asesoría a todos los organismos involucrados en materia de contratación de publicidad estatal (artículo 16). Por su parte, el Consejo de Comunicación Audiovisual - un organismo regulador independiente de la radiodifusión en Uruguay - se encarga de elaborar investigaciones y encuestas sobre el alcance, cobertura y sintonía de los medios de comunicación en sus distintas plataformas para ser remitida a los organismos públicos a manera de insumo para sus decisiones en materia de contratación, así como recibir y analizar denuncias de otros organismos, actores involucrados en los procedimientos de contratación, organizaciones y ciudadanos por el incumplimiento de los principios, criterios y demás disposiciones de la norma. También debe realizar y publicar un informe anual relativo al estado de la contratación de publicidad y correcta aplicación de la norma (artículo 17). 


\section{Control externo y transparencia}

La propuesta normativa establece un régimen de "transparencia activa" en su artículo 6o., que obliga a todas las entidades contratantes a publicar la información correspondiente a los procedimientos de contratación en el portal de la ACGE. Asimismo, el Proyecto de Ley obliga a las entidades a publicar en su página web el monto total del presupuesto en cada ejercicio destinado a publicidad estatal en todas sus fases (diseño, planificación, producción, contratación y distribución), los planes anuales de inversión publicitaria y el detalle de la inversión ejecutada en el ejercicio anual anterior, incluyendo los montos destinados a la contratación y pago de comisiones a las agencias de publicidad, centrales de medios y otros intermediarios participantes en el proceso. Se deriva al reglamento la fijación de los lineamientos técnicos que permitirán la uniformidad, interacción, fácil ubicación y acceso a la información para el ciudadano.

Por otro lado, el artículo 7o. de la iniciativa legislativa establece el principio denominado "transparencia de mercado", por el cual se incorporan una serie de exigencias que deben cumplir los actores privados relacionados con los procedimientos de contratación, como publicar en sus portales electrónicos información sobre los montos de contratación y las características de la pauta publicitaria oficial recibida. Asimismo, las agencias de publicidad, las centrales de medios, además de los distintos intermediarios en el proceso, deberán publicar información detallada sobre el destino efectivo de los montos asignados por los organismos públicos contratantes, al igual que cualquier otro gasto que haya sido necesario para el cumplimiento de la contratación final.

Por último, el proyecto también obliga al Consejo de Comunicación Audiovisual a publicar anualmente un informe en el que rinda cuentas de las asignaciones de publicidad de las distintas entidades en forma sistematizada.

\section{REgUlación De LA PUBLICIDAD ESTATAL EN MÉXICO}

\section{Finalidady ámbito de aplicación de la regulación}

La norma que regula la publicidad estatal en México es la Ley General de Comunicación Social, publicada el 11 de mayo del 2018. A diferen- 
cia de las distintas normas estudiadas hasta el momento, la norma mexicana de publicidad estatal no nació a raíz del impulso de una iniciativa legislativa, sino a través de un mandato judicial. En efecto, en noviembre de 2017, la Suprema Corte de Justicia de la Nación (SCJN) emitió una resolución que ordenaba al Congreso emitir una ley que regulara la publicidad oficial al ser ésta, hasta entonces, inexistente.

No obstante las buenas intenciones de distintas organizaciones civiles y de la SCJN que tuvieron por finalidad producir una adecuada regulación en materia de publicidad estatal, el texto de la Ley General de Comunicación Social no ha cumplido con las expectativas puestas sobre ella. De esa forma, incluso las mismas organizaciones que impulsaron una regulación de la publicidad estatal han denunciado que el dispositivo finalmente aprobado incentivaría el uso proselitista de la publicidad oficial, además de promover un gasto discrecional y excesivo (Ángel 2018). Tanto el Relator Especial para la Libertad de Expresión de la CIDH, Edison Lanza, como el Relator Especial de las Naciones Unidas sobre la Promoción y Protección del Derecho a la Libertad de Opinión y de Expresión, David Kaye, en un informe especial conjunto sobre su misión en México, mostraron su preocupación por la nueva legislación. Señalaron en aquella ocasión que además de no cumplir con los principios básicos ni con las recomendaciones de organismos internacionales o expertos, "la ley no establece normas claras sobre sus objetivos, criterios y procedimientos de asignación y mecanismos de supervisión, dejando un amplio margen de discreción y abuso de las autoridades" (CIDH y RELE 2018). Finalmente, los relatores instaron al gobierno de México a modificar la legislación, para que ésta pueda comprender los principios y mejores prácticas de regulación en la materia.

Las campañas de comunicación social son definidas en el artículo 4o., inciso 1 de la norma mexicana, como "aquellas que difunden el quehacer gubernamental, acciones o logros de gobierno o estimulan acciones de la ciudadanía para acceder a algún beneficio o servicio público”. Esta definición ha sido criticada por organizaciones como Artículo 19, que han advertido que los logros de los gobiernos no deben ser considerados publicidad estatal, por lo que aquella definición puede generar una promoción excesiva y arbitraria de la administración y de sus funcionarios (Ángel 2018). 
Por otro lado, la norma puntualiza que se encuentran fuera de su alcance de control las informaciones que deban publicarse o difundirse por mandato legal.

Entre los fines de las campañas estatales enumerados en el artículo 8o. de la Ley, se encuentran la promoción de la difusión de valores y derechos constitucionales, de campañas de turismo, educación, salud y protección civil, la información a los ciudadanos de sus derechos y obligaciones, el anuncio de medidas preventivas de riesgos, la difusión de las lenguas nacionales y el patrimonio histórico de la nación, así como la comunicación de programas y actuaciones públicas.

La difusión de publicidad estatal en medios de comunicación queda prohibida todo el tiempo que comprenden las campañas electorales federales y locales, hasta la conclusión de los comicios, con excepción de las campañas relativas a los servicios educativos y de salud, las de protección civil en caso de emergencia nacional, y cualquier otra que haya sido autorizada por el Instituto Nacional Electoral de manera específica durante los procesos electorales.

\section{Contratación y distribución de publicidad}

El artículo 5o. de la ley mexicana señala que las entidades de la administración, en el ejercicio del gasto público en materia de comunicación social, deberán tener presente como principios rectores la eficacia, eficiencia, economía y racionalidad presupuestaria, transparencia y máxima publicidad, honradez, objetividad e imparcialidad, institucionalidad, necesidad, congruencia y veracidad de la información. Asimismo, la disposición concluye que en materia de contratación de publicidad estatal se deberá atender al respeto a la libertad de expresión y al fomento del acceso ciudadano a la información.

El artículo 19 de la norma señala que la contratación de los tiempos con los medios de comunicación deberá apegarse a la legislación correspondiente en materia de adquisiciones, arrendamiento y servicios. No obstante, no establece las mismas pautas para las relaciones contractuales que deberá seguir el Estado con partes distintas a los medios de comunicación, como lo son las agencias de publicidad encargadas del proceso creativo y producción de una campaña, o las centrales de medios, em- 
presas que fungen como intermediarios entre el anunciante y el medio de comunicación.

El órgano que tiene la función más importante en el esquema de la publicidad estatal en México es la Secretaría de Gobernación (Segob), que ejerce funciones políticas y tiene a su cargo la coordinación con el resto del gabinete para el cumplimiento de los lineamientos establecidos por el presidente.

Según la norma, la Segob es la entidad encargada de regular, a nivel nacional, el gasto en materia de comunicación social. Para la publicidad estatal de envergadura federal o regional, la entidad administradora de estas funciones serán las dependencias o unidades administrativas en los ámbitos federales y municipales. Llama la atención la elección de la Segob como ente rector de la publicidad estatal en vista de que se trata de una institución encargada principalmente de tareas políticas. Ello, de manera peligrosa, podría derivar en la toma de decisiones fundadas en criterios políticos y no técnicos.

Las entidades públicas que deseen contratar publicidad deberán elaborar primero una estrategia de comunicación social. Igualmente, las entidades públicas también se encuentran obligadas a desarrollar un programa anual de comunicación social, que tiene como objetivo establecer las prioridades temáticas de las campañas y su cronología de difusión a efecto de dar cumplimiento a la Estrategia.

Para asignar la contratación estatal, se enumeran algunos criterios generales en el artículo 26 de la nueva norma, como la relación directa con las atribuciones y facultades de los sujetos obligados; que los recursos a utilizar sean proporcionales a los objetivos de la campaña, las herramientas y medios utilizados para la difusión de la campaña sean seleccionados de manera efectiva a fin de que alcance al público objetivo, los objetivos sean claros y precisos para comunicar y se establezcan metas de resultados y procedimientos de evaluación de las campañas, entre otros.

\section{Control externo y transparencia}

La regulación mexicana establece a la transparencia como principio rector del gasto en publicidad (artículo 5o.), y exige a las entidades dar a conocer públicamente y a mantener actualizada en sus páginas webs in- 
formación "sobre los montos destinados a gastos relativos a campañas de comunicación social desglosada por tipo de medio, proveedores, número de contrato y concepto o campaña, de conformidad con la legislación aplicable" (artículo 40). A pesar de esta exigencia de transparencia, la regulación es deficiente, al no obligar a las entidades a publicar los criterios que se han utilizado para la elección de medios. Con ello, la discrecionalidad que tienen los funcionarios al momento de elegir a determinados medios no ha sido del todo mitigada.

Asimismo, la norma dispone que las entidades publiquen en sus portales de transparencia un informe semestral sobre el gasto en publicidad, que debe contener, cuando menos, información referida a los recursos presupuestarios usados en cada campaña, los proveedores con los que ha trabajado, la fase de contratación en la que se encuentra y los montos de los pagos realizados a los medios de comunicación.

Como mecanismo de control, la normativa exige a las entidades, registrar mensualmente la información sobre las erogaciones en materia de publicidad estatal en un portal de la Secretaría de la Función Pública. Cada uno de estos informes mensuales deberá contener información relativa a la partida de gasto afectada, fecha de erogación, descripción del servicio contratado, unidad de medida, cantidad, costo o tarifa contratada, monto total erogado y nombre de las personas individuales contratadas (artículo 33).

Por otro lado, como mecanismo de control político, las entidades del gobierno mexicano se encuentran obligadas a remitir bimestralmente a la Cámara de Diputados, o a los congresos locales cuando se trate de publicidad oficial local, información relacionada con la ejecución de los programas y actividades del gobierno. Dicho informe, según el artículo 42 de la Ley, deberá incluir el monto total erogado por la dependencia en publicidad, el nombre de las empresas que prestaron sus servicios y el tipo de propaganda contratada.

Por último, la norma establece un sistema de infracciones que sanciona la no observancia de los principios de la norma al momento de la difusión de publicidad, así como exceder los límites y condiciones fijadas en los planes anuales y, de forma general, cualquier incumplimiento a la ley de publicidad estatal mexicana. A pesar del establecimiento de las causales de infracción, la norma no proporciona información adicional que 
detalle el procedimiento sancionador y sus implicancias para las entidades y sus funcionarios.

\section{ANÁlisis COMPARADO A LA LUZ DE LOS PRINGIPIOS DE LA REGULACIÓN DE LA PUBLICIDAD OFICIAL Y LIBERTAD DE EXPRESIÓN SOBRE PUBLICIDAD OFICIAL}

Probablemente el documento que mejor ha desarrollado las reglas básicas que debería contener una norma sobre publicidad estatal son los Principios sobre Regulación de la Publicidad Oficial y Libertad de Expresión, publicados por la RELE en 2012.

Este reporte sistematiza los principales aspectos que debería contemplar la regulación de la publicidad oficial, de modo tal que se garanticen principios esenciales, como la transparencia, la racionalidad en el gasto, la eficiencia y la competencia, al mismo tiempo que se respete la libertad de expresión y no se utilice la pauta publicitaria estatal como un mecanismo de premio o castigo a los medios de comunicación.

En los siguientes cuadros resumimos el cumplimiento de las legislaciones nacionales revisadas en nuestro estudio con los estándares señalados en los Principios de la RELE y destacamos las principales virtudes y falencias de dichas regulaciones.

\section{1. Ámbito de aplicación}

$\mathrm{Al}$ comparar la legislación peruana sobre publicidad estatal con los estándares de la RELE, se aprecia como aspecto destacable su amplio alcance de aplicación, al contemplar a todas las instancias y niveles del Estado (gobierno central - Poder Ejecutivo, Legislativo y Judicial-, gobiernos regionales y locales). Se trata de una característica positiva que comparte, por ejemplo, con la legislación uruguaya.

En cambio, la Ley 28874 falla por omisión, al regular únicamente la relación contractual entre entidades públicas y medios de comunicación y deja de lado a las agencias de creación y producción de publicidad y a las centrales de medios. Por oposición, tanto Canadá como Uruguay norman de manera detallada el proceso de creación y difusión de publicidad estatal desde sus fases iniciales. 
Vale la pena resaltar el caso de Canadá respecto de la contratación de centrales de medios. Como fue indicado previamente, el gobierno de Canadá, a través de la Agency of the Record, negocia y compra los tiempos y espacios publicitarios estatales, lo que le permite obtener una mejor optimización de los recursos al aprovechar el poder de compra colectivo, adquiriendo espacios publicitarios para más de un ministerio a la vez.

TABLA 1. Ámbito de aplicación de la legislación sobre publicidad estatal.

Cumplimiento de las legislaciones nacionales con los Principios sobre Regulación de la Publicidad Oficial y Libertad de Expresión de la RELE

\begin{tabular}{|l|c|c|c|c|}
\hline \multicolumn{1}{|c|}{ Principios RELE } & Perú & Canadá & Uruguay & México \\
\hline Creación y producción de publicidad & $X$ & $\checkmark$ & $\checkmark$ & $X$ \\
\hline Centrales de medios & $X$ & $\checkmark^{4}$ & $\checkmark$ & $X$ \\
\hline Medios de comunicación & $\checkmark$ & $\checkmark$ & $\checkmark$ & $\checkmark$ \\
\hline Todos los niveles del Estado & $\checkmark$ & $\downarrow^{5}$ & $\checkmark$ & $\checkmark$ \\
\hline
\end{tabular}

\section{Objetivos de la publicidad}

Cuando los objetivos legítimos que plantea la regulación peruana son contrastados con el resto de países analizados y los principios de la RELE, es posible apreciar que aquéllos resultan positivos en su mayoría; por ejemplo, proponer que la información difundida sea del interés público que la entidad anunciante está encargada de tutelar, y que la publicidad no sea engañosa, no induzca a la confusión del ciudadano ni se convierta en una forma de propaganda política.

Es enigmático el caso de México, cuya regulación ha sido objeto de fundadas críticas por parte de organizaciones especializadas. La definición de publicidad estatal mexicana incluye la difusión de los logros del gobierno, con lo que incumple de manera deliberada la recomendación de la RELE, que sugiere que ésta no puede ser pasible de uso como propaganda política o electoral. Algo similar se podría argumentar respecto

4 Referido a la figura del Agency of the Record.

5 El ámbito de aplicación sólo abarca al Poder Ejecutivo.

Esta obra está bajo una Licencia Creative Commons

Atribución-NoComercial-SinDerivar 4.0 Internacional, IIJ-UNAM.

Boletín Mexicano de Derecho Comparado, núm. 157, enero-abril de 2020, pp. 355-383. 
de la legislación peruana, en la medida en que ésta no impide la difusión de los "logros" de las entidades públicas, y más bien este tipo de mensajes podrían calzar dentro de uno de los objetivos permitidos por la ley, consistente en "la promoción de la imagen institucional".

Por otra parte, la norma peruana es la única de las analizadas que no contiene un mandato de suspensión de la publicidad estatal en época electoral. Sí existe en la Ley de Radio y Televisión una obligación de ese estilo, que tan sólo opera en esas dos plataformas de comunicación.

Las experiencias comparadas estudiadas son ambivalentes respecto de si la suspensión de la publicidad afecta a todas las etapas de la creación publicitaria o nada más prohíbe su fase final, es decir, la de difusión.

TABLA 2. Objetivos y reglas básicas del contenido de la publicidad. Cumplimiento de las legislaciones nacionales con los Principios sobre Regulación de la Publicidad Oficial y Libertad de Expresión de la RELE

\begin{tabular}{|l|c|c|c|c|}
\hline \multicolumn{1}{|c|}{ Principios RELE } & Perú & Canadá & Uruguay & México \\
\hline $\begin{array}{l}\text { Difusión de información de interés } \\
\text { público }\end{array}$ & $\checkmark$ & $\checkmark$ & $\checkmark$ & $\checkmark$ \\
\hline No engañosa & $\mathfrak{f}^{6}$ & $\checkmark$ & $\checkmark$ & $\checkmark$ \\
\hline No inducir a confusión & $\mathfrak{f}^{7}$ & $\checkmark$ & $\checkmark$ & $\checkmark$ \\
\hline No propaganda de gobierno & $\checkmark$ & $\checkmark$ & $\checkmark$ & $X$ \\
\hline No atacar a opositores ni críticos & $X$ & $\checkmark$ & $\checkmark$ & $\checkmark$ \\
\hline $\begin{array}{l}\text { Suspensión en época electoral } \\
\text { salvo excepciones (por ejemplo, } \\
\text { emergencia) }\end{array}$ & $f^{8}$ & $\checkmark$ & $\checkmark$ & $\checkmark$ \\
\hline
\end{tabular}

\section{Criterios de distribución}

En principio, la ley peruana que regula la publicidad estatal sí señala criterios adecuados de distribución de la pauta publicitaria, al igual que las regulaciones analizadas en Canadá y Uruguay. Todas las normas comparadas obligan a las entidades contratantes a tomar en cuenta el criterio

6 Sólo opera para la publicidad comercial.

7 Idem.

8 Solo opera para radio y televisión. 
más objetivo: el precio de los servicios. No obstante, México falla al no observar otros criterios básicos de distribución, como el público objetivo de la campaña publicitaria y la circulación o audiencia de los medios contratados. Una falencia de la legislación peruana es no contemplar con precisión la circulación o audiencia como factor de relevancia, e incluir uno de menor efectividad, como la cobertura.

Uruguay es el único país cuya regulación sistematiza los distintos criterios de distribución y les asigna un mecanismo de ponderación. Consideramos ello una buena práctica, en tanto busca mitigar la discrecionalidad de los funcionarios y ayuda a la transparencia y vigilancia ciudadana sobre el gasto de los recursos públicos.

Finalmente, en el Perú, al igual que en México y Uruguay, de manera contraria a las recomendaciones de la RELE, ciertas decisiones asociadas a la contratación de publicidad recaen en funcionarios políticos y no técnicos o, cuando menos, no existe una regla al respecto.

TABLA 3. Criterios de distribución de publicidad estatal. Cumplimiento de las legislaciones nacionales con los Principios sobre Regulación de la Publicidad Oficial y Libertad de Expresión de la RELE

\begin{tabular}{|l|c|c|c|c|}
\hline \multicolumn{1}{|c|}{ Principios RELE } & Perú & Canadá & Uruguay & México \\
\hline Público objetivo & $\checkmark$ & $\checkmark$ & $\checkmark$ & $X$ \\
\hline Circulación o audiencia & $\downarrow^{9}$ & $\checkmark$ & $\checkmark$ & $X$ \\
\hline Precio & $\checkmark$ & $\checkmark$ & $\checkmark$ & $\checkmark$ \\
\hline Mecanismo de ponderación (pesos relativos) & $X$ & $X$ & $\checkmark$ & $X$ \\
\hline $\begin{array}{l}\text { Decisión de asignación recae en funcionarios } \\
\text { técnicos (y no políticos) }\end{array}$ & $X$ & $\checkmark$ & $\checkmark^{10}$ & $X$ \\
\hline
\end{tabular}

\section{Planificación}

La totalidad de las normas nacionales estudiadas contienen disposiciones que exigen a las distintas entidades de la administración que reali-

9 No incluye circulación o audiencia del medio de comunicación, sino sólo la cobertura.

10 Son los mismos ministerios los que deciden la asignación.

Esta obra está bajo una Licencia Creative Commons

Atribución-NoComercial-SinDerivar 4.0 Internacional, IIJ-UNAM.

Boletín Mexicano de Derecho Comparado, núm. 157, enero-abril de 2020, pp. 355-383. 
cen una adecuada planificación de las campañas concretas de publicidad estatal a emprenderse, siguiendo los principios de la RELE.

Por lo general, las regulaciones instauran procedimientos multisectoriales, que buscan garantizar un control interno y externo del gasto en publicidad. En países como Canadá, por ejemplo, participan activamente en las actividades publicitarias hasta más de tres entidades de manera conjunta. La escasa preparación de las campañas publicitarias en algunos países como el Perú se explica más que por una deficiencia legislativa, por el poco profesionalismo y por la ausencia de mecanismos de coordinación que les permita aprovechar las sinergias y el know how en algunas entidades públicas.

TABLA 4. Planificación de campañas concretas. Cumplimiento de las legislaciones nacionales con los Principios sobre Regulación de la Publicidad Oficial y Libertad de Expresión de la RELE

\begin{tabular}{|l|c|c|c|c|}
\hline \multicolumn{1}{|c|}{ Principios RELE } & Perú & Canadá & Uruguay & México \\
\hline Campañas concretas & $\checkmark$ & $\checkmark$ & $\checkmark$ & $\checkmark$ \\
\hline
\end{tabular}

\section{Mecanismos de contratación}

Los mecanismos de contratación de las actividades publicitarias de los Estados, según los principios de la RELE, deben ser abiertos, transparentes, públicos y no discriminatorios. La ley peruana y la norma mexicana de publicidad estatal cumplen parcialmente con algunos criterios. Por oposición, Canadá y Uruguay sí poseen regulaciones que satisfacen el modelo regional de buenas prácticas regulatorias.

Por ejemplo, la legislación peruana no establece la posibilidad de hacer seguimiento al procedimiento de contratación publicitaria mientras éste se lleva a cabo, ni de impugnar algunas decisiones de los organismos públicos contratantes.

Perú y México tampoco prevén modelos que limiten la contratación directa, sin un proceso competitivo previo, o que la establezcan sólo para casos excepcionales. Canadá, por oposición, dispone que la contratación entre las entidades públicas y los medios de comunicación sólo podrá ser directa cuando el gasto sea menor a $\$ 25,000$. 
TABLA 5. Mecanismos de contratación. Cumplimiento de las legislaciones nacionales con los Principios sobre Regulación de la Publicidad Oficial y Libertad de Expresión de la RELE

\begin{tabular}{|l|c|c|c|c|}
\hline \multicolumn{1}{|c|}{ Principios RELE } & Perú & Canadá & Uruguay & México \\
\hline Abiertos & $X$ & $\checkmark$ & $\checkmark$ & $X$ \\
\hline Transparentes y públicos & $X$ & $\checkmark$ & $\checkmark$ & $X$ \\
\hline No discriminatorios & $\mathfrak{f}^{11}$ & $\checkmark$ & $\checkmark$ & $X$ \\
\hline $\begin{array}{l}\text { Contratación cerrada o directa sólo } \\
\text { por excepción }\end{array}$ & $X$ & $\checkmark^{12}$ & $\checkmark$ & $X$ \\
\hline $\begin{array}{l}\text { Posibilidad de cuestionar irregulari- } \\
\text { dades }\end{array}$ & $X$ & $\checkmark$ & $\checkmark$ & $\checkmark$ \\
\hline
\end{tabular}

\section{Transparencia y acceso a la información}

Todos los países estudiados cumplen satisfactoriamente con exigir en su normativa transparentar información sobre las campañas realizadas, las entidades públicas contratantes y los medios de comunicación elegidos. En el caso canadiense, empero, no se detallan los montos invertidos en cada medio de comunicación. En el caso de México, la legislación de dicho país no exige, a diferencia del resto, difundir los criterios de contratación que utilizaron las entidades públicas anunciantes.

Respecto del principio de transparencia activa, el Perú, hasta el momento, no cuenta con una disposición que obligue a las entidades a difundir los resultados de sus campañas publicitarias ni las razones de contratación de las agencias creativas encargadas de elaborar la publicidad o centrales de medios, cuando se haya realizado.

Uruguay es el único país de los estudiados cuya norma establece la buena práctica de detallar los mecanismos de ponderación de sus criterios de contratación.

11 Se señala en la ley que la asignación de pauta publicitaria buscará no favorecer a una sola empresa.

12 Es contratación directa cuando el monto es menor a $\$ 25,000$.

Esta obra está bajo una Licencia Creative Commons

Atribución-NoComercial-SinDerivar 4.0 Internacional, IIJ-UNAM.

Boletín Mexicano de Derecho Comparado, núm. 157, enero-abril de 2020, pp. 355-383. 
TABLA 6. Transparencia y acceso a la información. Cumplimiento de las legislaciones nacionales con los Principios sobre Regulación de la Publicidad Oficial y Libertad de Expresión de la RELE

\begin{tabular}{|l|c|c|c|c|}
\hline \multicolumn{1}{|c|}{ Principios RELE } & Perú & Canadá & Uruguay & México \\
\hline Criterios de contratación & $\mathfrak{f}^{13}$ & $\mathfrak{f}^{14}$ & $\checkmark$ & $X$ \\
\hline Presupuesto & $\checkmark$ & $\checkmark$ & $\checkmark$ & $\checkmark$ \\
\hline Contratos y gastos & $\checkmark$ & $\downarrow^{15}$ & $\checkmark$ & $\checkmark$ \\
\hline $\begin{array}{l}\text { Distinción por medio, campaña y enti- } \\
\text { dad contratante }\end{array}$ & $\checkmark$ & $\checkmark$ & $\checkmark$ & $\checkmark$ \\
\hline Transparencia activa & $\mathfrak{f}^{16}$ & $\checkmark$ & $\checkmark$ & $\checkmark$ \\
\hline Resultados & $\checkmark$ & $\checkmark$ & $\checkmark$ & $X$ \\
\hline
\end{tabular}

\section{Supervisión}

En lo que a supervisión respecta, ninguno de los países que han sido materia del estudio tiene órganos autónomos de control y supervisión de la contratación de publicidad. En Perú y Uruguay la norma establece una supervisión por parte de órganos parcialmente autónomos o de entidades generales de control, como sucede con la Contraloría General de la República en el Perú.

Las auditorías periódicas y la elaboración de informes públicos son prácticas que sin duda aportan a la vigilancia ciudadana el correcto uso de los recursos públicos en publicidad estatal. Canadá, Uruguay y México cumplen con estas dos recomendaciones de la RELE de manera simultánea.

Todas las leyes comparadas analizadas instauran mecanismos de sanciones ante su incumplimiento. No obstante, las normas peruana y mexicana son genéricas y no establecen infracciones ni sanciones específicas.

\footnotetext{
13 No se especifican los mecanismos de ponderación.

14 Idem.

15 No se divulga información detallada sobre los importes específicos pagados a cada medio de comunicación.

16 No incluye resultados de la campaña publicitaria ni razones de contratación de empresas de elaboración de publicidad o centrales de medios.
} 
TABLA 7. Supervisión. Cumplimiento de las legislaciones nacionales con los Principios sobre Regulación de la Publicidad Oficial y Libertad de Expresión de la RELE

\begin{tabular}{|l|c|c|c|c|}
\hline \multicolumn{1}{|c|}{ Principios RELE } & Perú & Canadá & Uruguay & México \\
\hline Control por órgano autónomo & $\mathfrak{f}^{17}$ & $X$ & $\mathfrak{f}^{18}$ & $X$ \\
\hline Auditorías periódicas & $X$ & $\checkmark$ & $\checkmark$ & $\checkmark$ \\
\hline Informes públicos & $X$ & $\checkmark$ & $\checkmark$ & $\checkmark$ \\
\hline Sanciones & $\mathfrak{f}^{19}$ & $\checkmark$ & $\checkmark$ & $\mathfrak{f}^{20}$ \\
\hline
\end{tabular}

\section{Pluralismo}

El documento de la RELE establece como principio rector al pluralismo informativo, y por ello propone que los Estados destinen recursos a través de mecanismos de ayudas indirectas o subsidios explícitos o neutros, distintos a la utilización de la inversión publicitaria. Ningún país, tal como lo concibe el documento de la Relatoría, lleva a cabo estas políticas de búsqueda de pluralismo.

TABLA 8. Pluralismo. Cumplimiento de las legislaciones nacionales con los Principios sobre Regulación de la Publicidad Oficial y Libertad de Expresión de la RELE

\begin{tabular}{|l|c|c|c|c|}
\hline \multicolumn{1}{|c|}{ Principios RELE } & Perú & Canadá & Uruguay & México \\
\hline $\begin{array}{l}\text { Ayudas indirectas o subsidios (no asig- } \\
\text { nación de publicidad) para fomentar } \\
\text { pluralismo }\end{array}$ & $X$ & $X$ & $X$ & $X$ \\
\hline Subsidios ajenos a línea editorial & $X$ & $X$ & $X$ & $X$ \\
\hline
\end{tabular}

17 Se refiere al órgano nacional de control.

18 El organismo de supervisión es relativamente autónomo.

19 No se especifican las sanciones.

20 Idem.

Esta obra está bajo una Licencia Creative Commons

Atribución-NoComercial-SinDerivar 4.0 Internacional, IIJ-UNAM.

Boletín Mexicano de Derecho Comparado, núm. 157, enero-abril de 2020, pp. 355-383. 


\section{CONCLUSIÓN}

El presente estudio ha servido para revisar las distintas políticas legislativas sobre regulación de publicidad oficial en países que pueden constituir un referente por la existencia de una ley expresa en la materia, así como por el tiempo que vienen aplicándola. Ello, además, debería servir de guía para la elaboración de propuestas legislativas o reglamentarias que busquen mejorar los marcos normativos existentes en la región.

La premura a la que hacíamos referencia al inicio con la que se han presentado y hasta aprobado iniciativas legislativas en materia de publicidad estatal en países como el Perú, no se contrapone con el adecuado entendimiento de los objetivos que debería buscar una ley que regule la publicidad oficial. Así, la mayoría de proyectos normativos presentados no siguen las mejores prácticas internacionales en la materia, ni siquiera ayudan a corregir las falencias de la regulación peruana aquí expuestas.

Finalmente, el estudio de la experiencia comparada es parte fundamental para la discusión sobre la regulación de la publicidad estatal, pero ésta necesariamente debe ser complementada con una revisión empírica del cumplimiento y la forma de aplicación de las obligaciones existentes. Así, el acceso a la información pública y la transparencia estatal activa se convierten no sólo en piezas vitales de la vigilancia ciudadana sobre el gasto estatal y el respeto de los derechos a la información de los ciudadanos y las libertades de expresión de los medios de comunicación y otros actores que intervienen en el proceso publicitario, sino que también son los pilares para la generación de evidencia que permitan la mejora continua en la regulación de la creación, planificación, adjudicación y supervisión de la publicidad estatal.

\section{BIBLIOGRAFÍA}

ÁNGEL, Arturo. 2018. "Nueve fallas clave en iniciativa del PRI sobre publicidad oficial, según Artículo 19", disponible en: https://wrereanimalpolitico.com/2018/03/publicidad-oficial-iniciativa-pri/.

Asociación por los Derechos Civiles. 2008. "Legislación comparada sobre regulación de publicidad oficial", disponible en: http://wrww2.congreso. gob.pe/sicr/cendocbib/con4_uibd.nsf/E07D9A4A2C58CB8505257E27005 D41CB/\$FILE/LEG_COMPARADA.pdf. 
Asociación por los Derechos Civiles. 2006. "Principios básicos para la regulación de la publicidad oficial", disponible en: http://wrere.corteidh. or.cr/tablas/29559.pdf.

Becerra, Martín. 2011. "Quid pro quo. La publicidad oficial en la Argentina y sus múltiples facetas", disponible en: https://martinbecerra.files.word press.com/2015/10/po-pc-mb-quid-pro-quo-final-2012.pdf.

BUQUET, Gustavo et al. 2012. "Ni premio ni castigo", disponible en: https://library.fes.de/pdf-files/bueros/uruguay/09456.pdf.

Centro de Archivos y AGCeso a la Información Pública. 2019. "CAinfo lamenta que Senado no aprobó proyecto sobre publicidad oficial", septiembre, 10, disponible en: https://wrere.cainfo.org.uy/2019/09/ cainfo-lamenta-que-senado-no-aprobo-proyecto-sobre-pu blicidad-oficial.

COMISIÓN INTERAMERICANA DE DEREGHOS Humanos y RELATORÍA ESPECIAL PARA LA LIBERTAD DE EXPRESIÓN DE LA COMISIÓN INTeramericana de Derechos Humanos. 2018. "Informe especial sobre la situación de la libertad de expresión en México: Informe conjunto del Relator Especial para la libertad de expresión de la CIDH y el Relator Especial de las Naciones Unidas sobre la promoción y protección del derecho a la libertad de opinión y de expresión sobre su misión a México", disponible en: http://wreweoas.org/es/cidh/expresion/ docs/2018_06_18\%20CIDH-UN_FINAL_MX_report_SPA.PDF.

GOVERnMENT OF CANADA. 2016. "About Government Advertising", disponible en: https://wrwe.canada.ca/en/treasury-board-secretariat/services/ government-communications/government-advertising/about.html.

House of Commons CanadA. 2017. "Reaching Canadians with Effective Government Advertising: Report of the Standing Committee on Government Operations and Estimates", disponible en: http://wwre. ourcommons.ca/Content/Committee/421/OGGO/Reports/RP9298336/ oggorp12/oggorp12-e.pdf.

Public SERVICES ANd PRoCUREMeNt CANAdA. 2018. "2016 to 2017 Annual Report on Government of Canada Advertising Activities", disponible en: http://wrewe.tpsgc-pwgsc.gc.ca/pub-adv/rapports-reports/docu ments/rapport-annuel-annual-report-2016-2017-eng.pdf.

Public SERVICES AND PROCUREMENT CANADA. 2019a. "Frequently asked Questions", disponible en: http://wrere.tpsgc-pwgsc.gc.ca/pub-adv/faq-eng. html\#q5.1. 
Public Services and Procurement CaNada. 2019b. "Information for Industry", disponible en: https://wwretpsgc-pwgsc.gc.ca/pub-adv/ac-ar-eng. html.

RELATORÍA ESPECIAL PARA LA LIBERTAD DE EXPRESIÓN DE LA COMISiÓn InTERAMERICANA De Derechos Humanos. 2012. "Principios sobre Regulación de la Publicidad Oficial y Libertad de Expresión", disponible en: https://wrewe.oas.org/es/cidh/expresion/docs/publi caciones/ publicidad\%20oficial\%202012\%2005\%2007.pdf.

RUIZ, Albino. 2017. Limites en el poder. Aprobación presidencial y publicidad estatal, Lima, Ediciones Braudel.

WAN-INFRA (Asociación Mundial de Periódicos y Editores de Noticias). 2014. "Comprando complacencia: publicidad oficial y censura indirecta en México", disponible en: http://wrww2.congreso.gob.pe/sicr/cendocbib/ con4_uibd.nsf/C29F568AC9E1830305257E3000791F50/\$FILE/1_pdfsam_215095601.pdf.

WAN-INFRA (Asociación Mundial de Periódicos y Editores de Noticias). 2015. "Censura indirecta en México: rompiendo promesas, bloqueando reformas", disponible en: https://wrewewan-ifra.org/sites/default/fi les/field_article_file/SoftCensorship\%20Mexico\%202015\%20ES\%20upda te\%20final\%20.pdf.

Young, Sally. 2007. "A History of Government Advertising in Australia", disponible en: https://minerva-access.unimelb.edu.au/bitstream/handle/ 11343/25943/115198_4700.pdf. 